\title{
Radiosensitizing effect of oleanolic acid on tumor cells through the inhibition of GSH synthesis in vitro
}

\author{
JUAN WANG, MAOHU YU, LINLIN XIAO, SHIGUO XU, QIYI YI and WENSEN JIN \\ Teaching and Research Section of Nuclear Medicine, Anhui Medical University, Hefei, Anhui 230032, P.R. China
}

Received January 15, 2013; Accepted April 8, 2013

DOI: $10.3892 /$ or.2013.2510

\begin{abstract}
Oleanolic acid (OA) is a natural pentacyclic triterpenoid that has been used in traditional medicine as an anticancer and anti-inflammatory agent. The aim of our study was to investigate whether or not OA increases the radiosensivity of tumor cells, and the relative mechanism was also investigated. Clonogenic assay was used to observe the radiosensitivity of C6 and A549 cells following different treatments. The alteration of intracellular DNA damage was determined using a micronucleus (MN) assay. In order to identify the mechanism of OA-mediated radiosensitization of tumor cells, the levels of glutathione (GSH) in irradiated cells following various pretreatments were determined using glutathione reductase/5,5'-dithiobis-(2-nitrobenzoic acid) (DTNB) recycling assay. Under the same condition, the activities of $\gamma$-glutamylcysteine synthetase $(\gamma$-GCS) and GSH synthase (GSS), both key enzymes for GSH synthesis, were detected using appropriate methods. In order to confirm the radiosensitizing effect of OA on cancer cells by attenuating $\mathrm{GSH}, \mathrm{N}$-acetylcysteine (NAC) was added to cells in culture for $12 \mathrm{~h}$ before irradiation. The results showed that the combined treatment of radiation with OA significantly decreased the clonogenic growth of tumor cells and enhanced the numbers of intracellular MN compared to irradiation alone. Furthermore, it was found that the synthesis of cellular GSH was inhibited concomitantly with the downregulation of $\gamma$-GCS activity. Therefore, the utilization of OA as a radiosensitizing agent for irradiation-inducing cell death offers a potential therapeutic approach to treat cancer.
\end{abstract}

\section{Introduction}

Radiotherapy is an effective tool for malignant tumor treatments. It is particularly beneficial for rapidly growing tumors due to their high susceptibility to radiation $(1,2)$. Ionizing

Correspondence to: Dr Wensen Jin, Teaching and Research Section of Nuclear Medicine, Anhui Medical University, 81 Meishan Road, Hefei, Anhui 230032, P.R. China

E-mail: wensenjn@139.com

Key words: oleanolic acid, radiosensitizing effect, glutathione, irradiation radiation can produce high amounts of reactive oxygen species (ROS) and free radicals, which further induce cellular DNA single-strand breaks (SSBs) and double-strand breaks (DSBs), eventually resulting in the death of cancer cells $(3,4)$. However, local failure after irradiation remains a challenge due to intrinsic and acquired resistance of tumor cells to radiation treatment (5).

Cellular antioxidants are important for the protection of cells against ROS and free radicals generated through endogenous or exogenous oxidative stress (6-8). Glutathione (GSH), the tripeptide thiol L- $\gamma$-glutamyl-L-cysteinyl-glycine, is one of the most abundant antioxidants in the cells with concentrations in the low millimolar range. It plays a key role in maintaining intracellular redox equilibrium and in augmenting cellular defenses to harmful factors $(9,10)$. In general, GSH is synthesized from its constituent amino acids, glutamic acid, cysteine and glycine, via two sequential ATP-consuming steps, which are catalyzed by $\gamma$-glutamylcysteine synthetase $(\gamma$-GCS) and GSH synthase (GSS). The synthesis of the di-peptide $\gamma$-glutamylcysteine by $\gamma$-GCS is the rate-limiting step in de novo GSH synthesis $(11,12)$. The level of GSH is reported to be increased in various types of tumor cells, for example in bone marrow, breast, glioma, colon, larynx and lung cancers (13-18). Owing to its protection, an increased level of GSH is often associated with a refractory response to ionizing radiation via GSH scavenging ROS and free radicals. Conversely, depletion of intracellular GSH favorably increases the radiosensitivity of cancer cells $(19,20)$.

Oleanolic acid (3b-hydroxy-olea-12-en-28-oic acid; OA) belongs to the triterpenoid family (Fig. 1), which is widely distributed in the plant kingdom (21). The pentacyclic triterpenoid with a wide variety of functional groups is commonly used to treat various diseases. OA demonstrates anti-inflammatory activity (22), protection against hepatotoxicity $(23,24)$, and recovery of the hematopoietic system after irradiation (25). Meanwhile, OA was found to induce differentiation of malignant cells, to inhibit proliferation of carcinoma cells and to promote apoptosis $(26,27)$. It has been well established that plant extracts and their derivatives have high potential capability as new anticancer therapeutic agents, either alone or in combination with conventional chemotherapeutic agents for cancers that exhibit resistance to standard drugs $(28,29)$. However, whether OA increases the radiotherapeutic effect on cancer cells or not remains unclear. Therefore, in the present study, we investigated the influence of the monomer OA on the 
radiosensitivity of cancer cells and the alteration in intracellular GSH level. Our results demonstrated that OA enhances the radiosensitivity of C6 and A549 cells through inhibition of intracellular GSH synthesis.

\section{Materials and methods}

Cell culture and treatment. The rat glioma C6 and human lung cancer A549 cell lines (Cell Bank, Chinese Academy of Sciences) were cultured in RPMI-1640 medium supplemented with $10 \%$ fetal bovine serum (FBS) (both from Gibco, Carlsbad, CA, USA), penicillin (100 U/ml) and streptomycin $(100 \mu \mathrm{g} / \mathrm{ml})$ (Sigma-Aldrich, St. Louis, MO, USA) at $37^{\circ} \mathrm{C}$ in an incubator containing a humid atmosphere of $95 \%$ air and $5 \%$ $\mathrm{CO}_{2}$ and propagated according to the protocol supplied by the American Type Culture Collection. OA was purchased from NanJing-Zelang (China) and dissolved in dimethyl sulfoxide (DMSO; Sigma-Aldrich) at a stock concentration of $250 \mu \mathrm{g} / \mathrm{ml}$ and stored at $-20^{\circ} \mathrm{C}$. All cells were treated with $\mathrm{OA}$ at different concentrations for $24 \mathrm{~h}$ prior to exposure to irradiation. In addition, $5 \mathrm{mM} \mathrm{N}$-acetylcysteine (NAC) (Sigma-Aldrich), an antioxidant and GSH precursor, was added to the cultured cells $12 \mathrm{~h}$ prior to irradiation in order to further confirm the mechanism of OA modulation of the radiosensitivity of tumor cells by influencing the GSH level.

Cell viability assay. The influence of $\mathrm{OA}$ on cell growth was determined using the 3-(4,5-dimethylthiazol-2-yl)-2,5diphenyltetrazolium bromide (MTT, Sigma-Aldrich) method. C6 and A549 cells were seeded in 96-well plates at a density of $5 \times 10^{3}$ cells/well. They were then treated with different concentrations of OA for $24 \mathrm{~h}$. Furthermore, the medium was replaced with fresh medium allowing cells to be continuously grown up to $72 \mathrm{~h}$. MTT dye was added to a final concentration of $0.5 \mathrm{mg} / \mathrm{ml}$, and cells were subsequently incubated for an additional $4 \mathrm{~h}$ at $37^{\circ} \mathrm{C}$. The medium containing residual MTT dye was carefully aspirated from each of the wells, and $200 \mu$ l DMSO was added to each well to dissolve the reduced formazan dye. The fraction of viable cells was calculated by comparing the optical absorbance of the culture exposed to OA treatment with that of the untreated control.

Irradiation. Irradiation was emitted using a 6-MV X-ray linear accelerator (Varian Inc., Palo Alto, CA, USA) at a dose rate of $250 \mathrm{cGy} / \mathrm{min}$.

Clonogenic assay. The radiosensitivity of tumor cells was determined using a clonogenic assay. Both tumor cell lines were seeded and cultured overnight at an appropriate density in T25 flasks, and subsequently different drugs were added into the medium for $24 \mathrm{~h}$. After being pretreated with control, $\mathrm{OA}$, or $\mathrm{OA}$ and NAC, cells were subjected to $0,1,2,3,5$, or 7 Gy X-ray irradiation. The medium was then replaced with fresh medium allowing cells to continuously grow for colony formation for 9 to 12 days. Cell colonies were fixed by absolute methanol and stained with Giemsa for counting. Clonogenic survival fraction (SF) was calculated as the number of colonies/(the number of seeded cells x plating efficiency). Plating efficiency was defined as the number of colonies/the number of seeded cells of the untreated control. Survival curve was

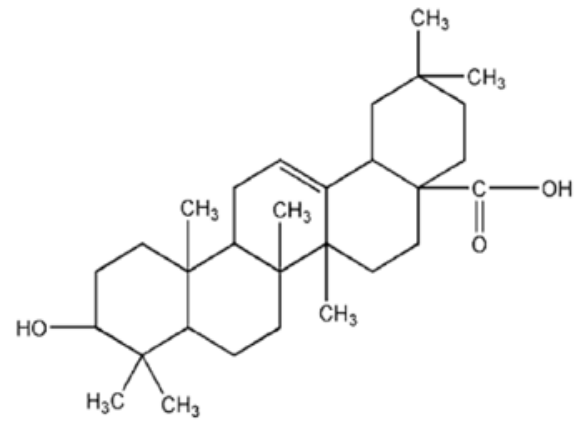

Figure 1. Chemical structural formula of oleanolic acid.

fitted with the single target multi-model of the equation: $S=1-1\left(1-e^{-D / D}\right)^{N}$.

Micronucleus assay. The number of micronuclei (MN) were measured with the cytokinesis-block technique as a biological end point for the response of mimetic hypoxia to irradiation. Briefly, the cells were exposed to $0.83 \mu \mathrm{g} / \mathrm{ml}$ cytochalasin B (Sigma-Aldrich) for 19-20 h followed by $75 \mathrm{mM} \mathrm{KCl}$ hypotonic treatment for 1-3 min and then fixed in situ with methanol:acetic acid $(9: 1 \mathrm{v} / \mathrm{v})$ for $30 \mathrm{~min}$. Air-dried cells were stained with 5\% Giemsa (Sigma-Aldrich) for $10 \mathrm{~min}$. Micronuclei were scored in binucleated cells, and the formation of binucleated cells was measured as the percentage of the total number of cells scored. For each sample, at least 1,000 binucleated cells were counted. The MN yield, $\mathrm{Y}_{\mathrm{MN}}$, was the ratio of the number of micronuclei to the number of binucleated cells scored.

Intracellular GSH assay. After triplicate samples of $10^{6}$ cells were treated with different reagents, the intracellular levels of GSH were measured with the glutathione reductase/5,5'dithiobis-(2-nitrobenzoic acid) (DTNB) recycling assay kit (Beyotime Biotechnology, Jiangsu, China) under the methods recommended by the manufacturer. Briefly, GSH was determined by using a reaction mixture, containing $50 \mu \mathrm{l}$ of cell lysates, $50 \mu \mathrm{l}$ of $2.4 \mathrm{mM}$ DTNB and $50 \mu \mathrm{l}$ of $10.64 \mathrm{mU} / \mu \mathrm{l}$ glutathione reductase in the assay buffer $(\mathrm{pH} 7.5)$ containing $153 \mathrm{mM}$ sodium phosphate and $8.4 \mathrm{mM}$ EDTA. After a 5-min incubation at $25^{\circ} \mathrm{C}$, the reaction was started by the addition of $50 \mu 1 \mathrm{NADPH}$ solution $(0.16 \mathrm{mg} / \mathrm{ml})$ in the assay buffer. The standard sample and checking sample cuvettes were placed into a dual-beam spectrophotometer, and the increases in absorbance at $412 \mathrm{~nm}$ were followed as a function of time.

Intracellular $\gamma$-GCS activity assay. Cells $\left(10^{6}\right)$ were homogenized in $50 \mathrm{mM}$ potassium phosphate $(\mathrm{pH} 7.5)$ containing TES/SB buffer (20 mM Tris, $1 \mathrm{mM}$ EDTA, $250 \mathrm{mM}$ sucrose, $20 \mathrm{mM}$ sodium borate, $2 \mathrm{mM}$ serine) for the $\gamma$-GCS assay. Homogenates were centrifuged at $12,000 \mathrm{rpm}\left(15 \mathrm{~min}, 4^{\circ} \mathrm{C}\right)$, and the supernatants were maintained on ice for determination of enzyme activity. The protein concentration of cell supernatants was measured using the Bio-Rad DC Protein Assay kit (Bio-Rad, Herts, UK), and the enzyme activity was reported as $\mathrm{U} / \mathrm{mg}$ protein, where a unit of activity was the amount of enzyme required to convert one micromole of substrate to product per min at $25^{\circ} \mathrm{C}$. The $\gamma$-GCS assay was an adaptation of a previously described method, in which $\gamma$-GCS in 



Figure 2. Cytotoxic effect of oleanolic acid (OA) on C6 and A549 cells. The growth inhibition of OA on (A) C6 cells and (B) A549 cells, respectively. ${ }^{* *} \mathrm{P}<0.01$, compared with control.

cell extracts synthesized $\gamma$-glutamylcysteine which was then reacted with 2,3-naphthalenedicarboxaldehyde (NDA) to form a highly fluorescent product that was able to be measured fluorimetrically at $520 \mathrm{~nm}(30)$.

Intracellular GSS activity assay. Tumor cells were plated in $60-\mathrm{mm}$ culture dishes at a density of $10^{6}$ cells/dish and then divided into different groups with various methods of pretreatment. The intracellular GSS activities were measured using GSS assay kit (Lanxu Biotech Co. Ltd., China). Briefly, the cells were subjected to repeated freeze-thaw cycles to lyse the cells for release of intracellular components. Cell lysates were centrifuged at 3,000 rpm $\left(20 \mathrm{~min}, 4^{\circ} \mathrm{C}\right)$, and the supernatants were maintained on ice for determination of enzyme activity. All procedures were performed according to the protocol of the kit. After the reaction was terminated, the absorbance was measured at $450 \mathrm{~nm}$ on an enzyme-linked immunosorbent assay (ELISA) reader. The activity of GSS in the sample was then determined by comparing the OD of the samples to the standard curve.

Statistical analysis. Data are reported as the means \pm SEM of 3 separate experiments. Statistical analysis was measured by the independent sample t-test and analysis of variance. $\mathrm{P}<0.05$ was considered to indicate a statistically significant result.

\section{Results}

Selection of the experimental concentration of $O A$. In order to select the experimental concentration of OA for this study, a $24 \mathrm{~h}$ dose-response study was conducted by exposing the cells lines to different concentrations of OA. The results of the MTT assay showed that the half inhibition concentration $\left(\mathrm{IC}_{50}\right)$ of OA for C6 cells was $35 \mu \mathrm{g} / \mathrm{ml}$ and for the A549 cells this value was $27 \mu \mathrm{g} / \mathrm{ml}$, respectively (Fig. 2). $10 \% \mathrm{IC}_{50}, 20 \% \mathrm{IC}_{50}$ and $30 \% \mathrm{IC}_{50}$ of drug concentrations were used to determine the influence of $\mathrm{OA}$ on the radiosensitivities of both tumor cell lines.
Influence of $O A$ on the radiosensitivities of the tumor cells. No statistically significant changes were noted in the formation of C6 and A549 clonogenic cells following treatment with different concentrations of OA. Based on the single target multi-model, the fitting curves of the irradiated C6 and A549 cells had a gradually declining tendency with increasing doses. The SFs of irradiated cells, after OA pretreatment for $24 \mathrm{~h}$, were further decreased when compared to those of the irradiated cells without OA treatment (Fig. 3). By calculating the $\mathrm{D}_{0}$ value and the sensitive enhancement ratio (SER), the $\mathrm{D}_{0}$ and SERs of irradiated cells were reduced in a OA concentration-dependent manner. When the concentration of OA reached $10 \% \mathrm{IC}_{50}, 20 \% \mathrm{IC}_{50}$ and $30 \% \mathrm{IC}_{50}$, the SERs of $\mathrm{C} 6$ and A549 cell were 1.16, 1.81, 2.23 and 1.13, 1.26, 1.55, respectively. In contrast, the treatment of NAC partially reduced the sensitizing effect of $\mathrm{OA}$ at $30 \% \mathrm{IC}_{50}$ on the irradiated cells. Therefore, OA obviously enhanced the radiosensitivity of both tumor cell lines.

Changes in the intracellular micronucleus rate by OA pretreatment. The results from the $\mathrm{MN}$ assay showed there was no obvious influence of the various concentrations of $\mathrm{OA}$ on the formation of the numbered $\mathrm{MN}$ in both cell lines unexposed to X-rays. Subsequently, the numbers of intracellular MN were significantly increased with concomitant irradiation doses. In both irradiated cell lines pretreatment with various concentrations of OA, further enhanced the numbers of intracellular MN. Meanwhile, it was found that, compared with the irradiated cells without $\mathrm{OA}$ treatment, the irradiated cells treated with $20 \% \mathrm{IC}_{50}$ and $30 \% \mathrm{IC}_{50}$ of OA displayed a statistically significant increase in cellular MN formation. Additionally, it was obvious that the capability of $30 \% \mathrm{IC}_{50}$ OA-induced $\mathrm{MN}$ generation in irradiated cells was reduced after NAC was added into the culture medium. These results indicate that $\mathrm{OA}$ prompts the generation of MN in irradiated tumor cells (Fig. 4).

Effect of OA on the GSH level. To further study the mechanism of the influence of $\mathrm{OA}$ on the radiosensitivity of tumor 

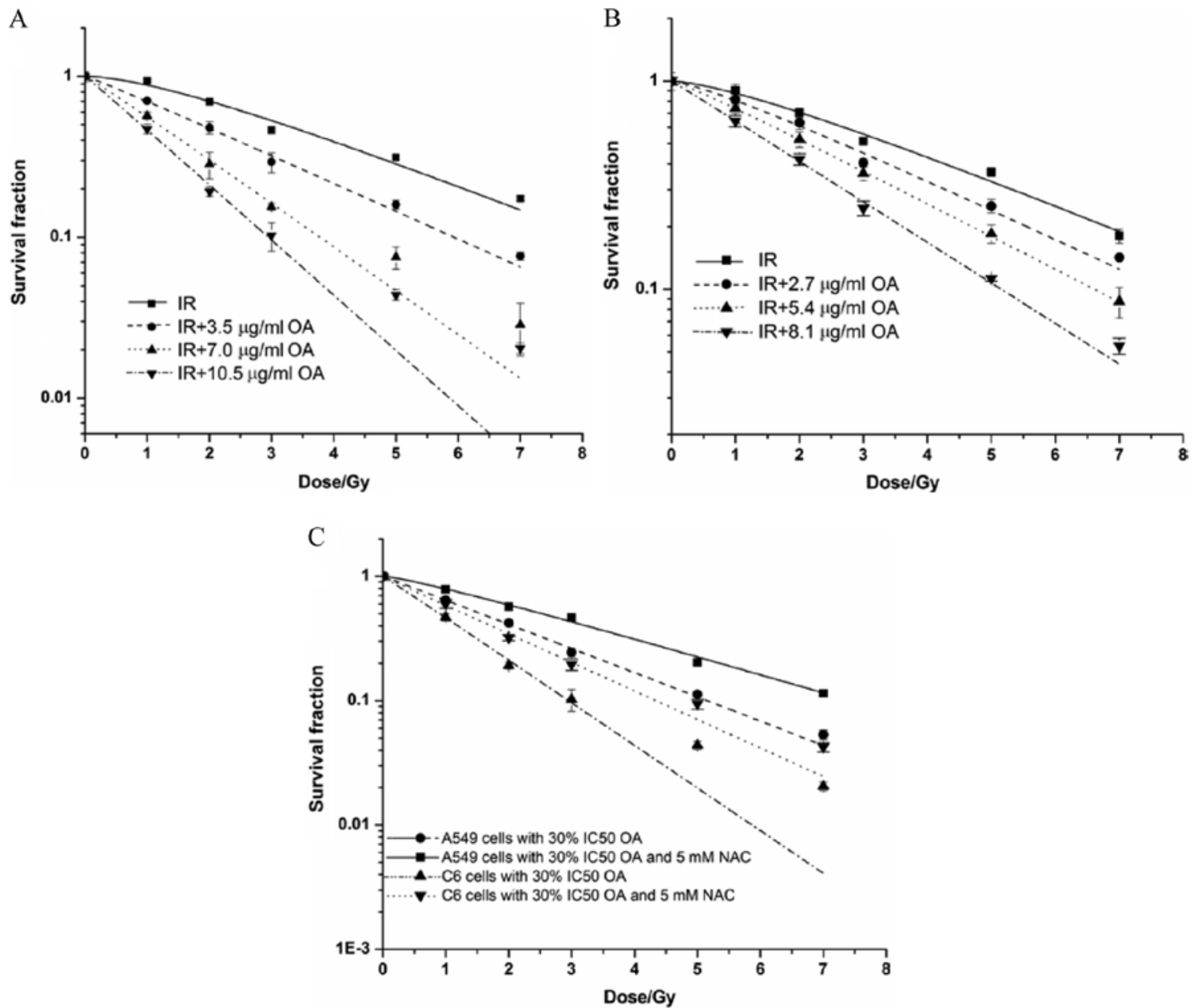

Figure 3. Radiosensitization of C6 and A549 cells following pretreatment with oleanolic acid (OA). (A) Clonogenic cell survival curves were obtained from C6 cells pretreated with different concentrations of $\mathrm{OA}$ for $24 \mathrm{~h}$ and then exposed to 1-7 Gy irradiation (IR). The $\mathrm{SERs}$ of $10 \% \mathrm{IC}_{50}, 20 \% \mathrm{IC}_{50}$ and $30 \% \mathrm{IC}_{50}$ concentrations of OA were 1.16, 1.81 and 2.23, respectively. (B) Cell survival curves were obtained from A549 cells pretreated similarly to C6 cells. The SERs of $10 \% \mathrm{IC}_{50}, 20 \% \mathrm{IC}_{50}$ and $30 \% \mathrm{IC}_{50}$ concentrations of OA were 1.13, 1.26 and 1.55, respectively. (C) Survival curves obtained from both cell lines following $30 \% \mathrm{IC}_{50} \mathrm{OA}$ and $5 \mathrm{mM}$ N-acetylcysteine (NAC) treatment. The data are from 3 independent experiments.

cells, intracellular GSH levels were measured after pretreatment with different concentrations of OA for $24 \mathrm{~h}$. As shown in Fig. 5, when compared with the cells in the absence of OA, significant decreases in the GSH levels of C6 cells in the presence of OA were noted. Furthermore, the same phenomenon was noted in A549 cells, where intracellular GSH levels showed a gradually declining tendency concomitant with increases in OA concentrations. In contrast, supplementation of NAC significantly restored the inhibition of GSH synthesis by OA. The results revealed that OA effectively inhibits the synthesis of GSH in tumor cells.

Inhibition of $\gamma$-GCS activity by OA. Since $\gamma$-GCS is the rate-limiting enzyme in the synthesis of intracellular GSH, its activity was further measured. As showed in Fig. 6, the activity of $\gamma$-GCS in C6 cells was inhibited by the treatment with $20 \% \mathrm{IC}_{50}$ and $30 \% \mathrm{IC}_{50}$ of OA, while no statistical reduction in the activity of $\gamma$-GCS was noted following $10 \% \mathrm{IC}_{50}$ of $\mathrm{OA}$ treatment. Unlike $\mathrm{C} 6$ cells, all concentrations of OA treatment inhibited the enzyme activity in A549 cells. The results indicated that NAC could not reverse the OA-inhibited activity of $\gamma$-GCS in both tumor cell lines. It was shown that OA has the capacity of inhibiting the activity of $\gamma$-GCS in tumor cells.

Influence of OA on the activity of GSS. GSS is another synthetic enzyme of GSH. Thus, the activity of GSS in both cell lines following OA treatment was determined. As shown in Fig. 7, we found that OA pretreatment failed to affect the intracellular activity of GSS in the C6 cells. A similar phenomenon was also observed in A549 cells when OA concentration was $10 \% \mathrm{IC}_{50}$ or $20 \% \mathrm{IC}_{50}$, even $30 \% \mathrm{IC}_{50}$ of OA could statistically enhance the activity of GSS. Meanwhile, compared to the cells treated with $30 \% \mathrm{IC}_{50}$ of OA, both $\mathrm{C} 6$ and $\mathrm{A} 549$ cells treated with $30 \% \mathrm{IC}_{50}$ of OA and NAC did not show an obvious alteration in GSS activity. The results thus revealed that OA does not decrease the activity of GSS in tumor cells.

\section{Discussion}

Ionizing radiation continues to be a frontline therapy for local control of glioma and lung cancer where surgery is either not possible or undesirable $(31,32)$. However, regarding the 

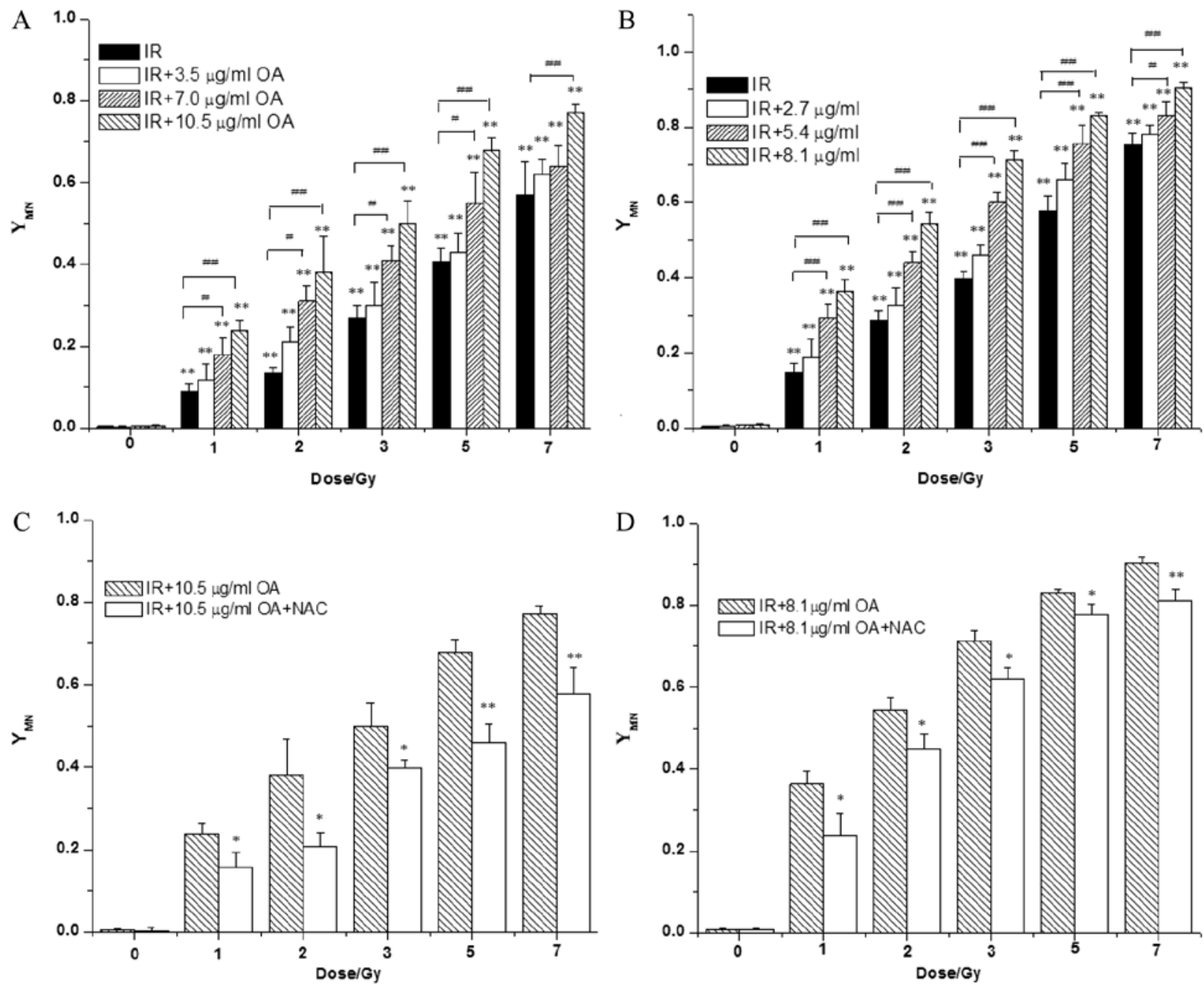

Figure 4. Alterations in the micronucleus rate of irradiated tumor cells by oleanolic acid (OA) pretreatment. Micronucleus (MN) induction in (A) $\mathrm{C} 6$ and (B) A549 cells irradiated with different doses of X-rays prior to OA treatment. The data are from three independent experiments. ${ }^{* *} \mathrm{P}<0.01$, compared to the $\mathrm{Y}_{\mathrm{MN}}$ of the same cell line without $\mathrm{OA}$ treatment and irradiation (IR). ${ }^{*} \mathrm{P}<0.05$ and ${ }^{\# \#} \mathrm{P}<0.01$, compared to the $\mathrm{Y}_{\mathrm{MN}}$ of the same irradiated cell line without $\mathrm{OA}$ treatment. (C and D) N-acetylcysteine (NAC) statistically reduces the enhancement of the ratio of $\mathrm{MN}$ by pretreatment with $30 \% \mathrm{IC}_{50} \mathrm{OA}$; C6 and A549 cells are shown in $\mathrm{C}$ and $\mathrm{D}$, respectively. ${ }^{*} \mathrm{P}<0.05$ and ${ }^{* *} \mathrm{P}<0.01$, compared to the $\mathrm{Y}_{\mathrm{MN}}$ of the same irradiated cell line without NAC treatment.

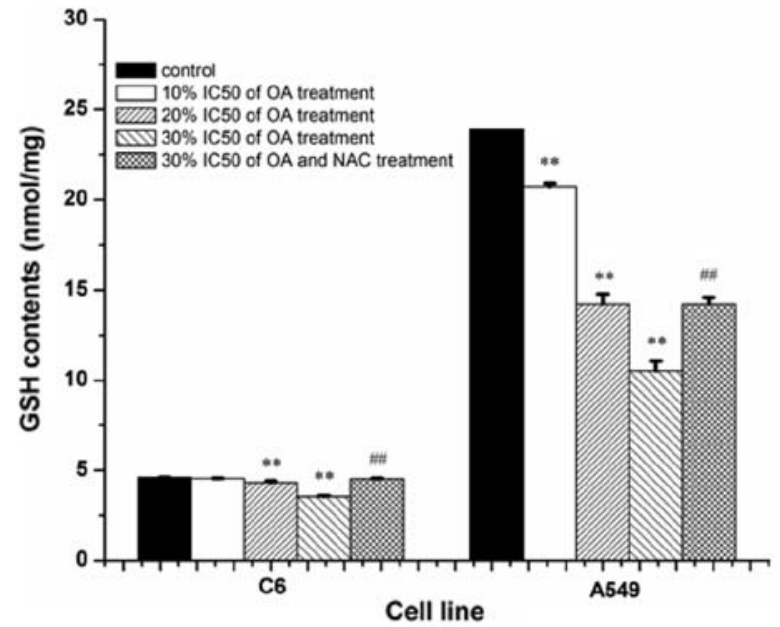

Figure 5. Inhibition of oleanolic acid (OA) on the synthesis of intracellular glutathione (GSH). Data are from 3 independent experiments. ${ }^{* * *} \mathrm{P}<0.01$, compared to the cells in the absence of $\mathrm{OA}$ treatment. ${ }^{\# \#} \mathrm{P}<0.01$, compared to the cells without $\mathrm{N}$-acetylcysteine (NAC) treatment.

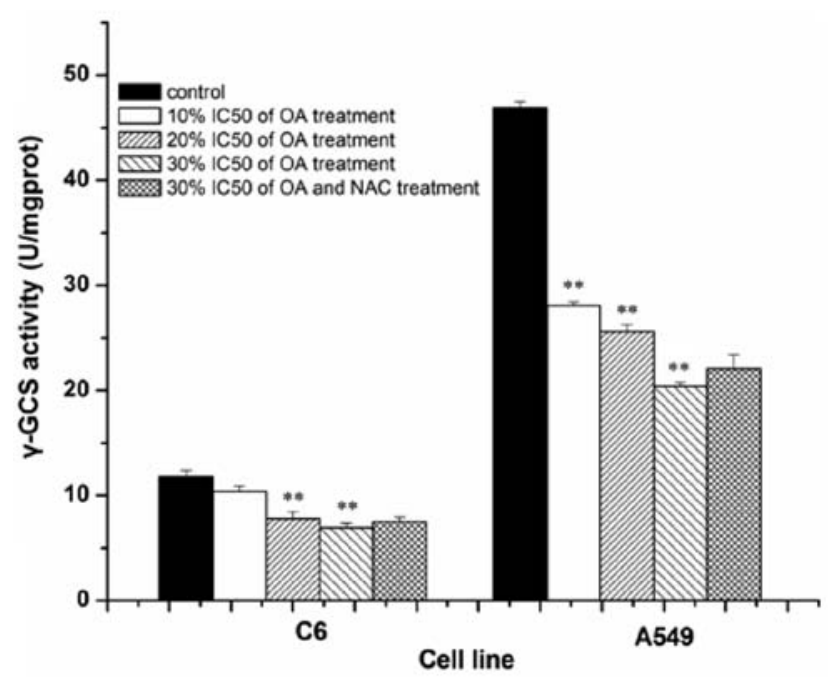

Figure 6. Inhibition of oleanolic acid (OA) on the activity of $\gamma$-glutamylcysteine synthetase $(\gamma$-GCS). Data are from 3 independent experiments. ${ }^{* *} \mathrm{P}<0.01$, compared to the cells in the absence of OA treatment. 




Figure 7. Influence of oleanolic acid (OA) on the activity of GSS. Data are from three independent experiments. ${ }^{*} \mathrm{P}<0.05$, compared to the cells in the absence of OA treatment.

radiotherapeutics of lung cancer, radiation pneumonia is one serious complication after patient exposure to high-dose irradiation (33). Thus, it is favorable to decrease the incidence of radiation pneumonia by enhancement of the radiosensitivity of cancer cells with pretreatment of a radiosensitizing agent. Regarding glioma, an appropriate radiosensitizing drug needs to have the capability for permeating the blood-brain barrier for achieving effective plasma concentrations in the region of the tumor. There are numerous natural compounds from the extracts of plants, which have the potential to increase the radiosensitivity of tumor cells (34-36). In the present study, we investigated the radiosensitizing effect of OA on glioma and lung cancer cell lines. The natural OA extract in the form of free acid has the ability of infiltrating the blood-brain barrier (37). The rationale for combined treatment of non-toxic concentrations of $\mathrm{OA}$ with radiation is to observe whether it leads to a greater extent of tumor cell death. We thus selected three different concentrations of OA, which had no obvious influence on cell viability, to carry out the radiosensitizing experiment. Different doses of radiation combined with OA greatly inhibited the cell growth and achieved an additive effect. According to the calculation of $\mathrm{D}_{0}$ and SERs, the sensitivity of tumor cells to radiation was significantly enhanced by OA treatment. In a previous study, the radiosensitizing effect of ursolic acid, an isomer of OA, was demonstrated in diverse cell types and in vivo (38). Additionally, experimental data indicate that betulinic acid, another pentacyclic triterpenoid, may be a useful agent for tumors that are resistant to irradiation such as head and neck cancer and melanoma $(39,40)$. The results from our research also support that OA has radiosensitizing capacities in tumor cells as confirmed by the effects of combined treatment of other pentacyclic triterpenoids and irradiation.

The protective effect of GSH is important for the resistance of cancer cells against radiotherapeutics. Many compounds of natural origin are capable of regulating intracellular GSH levels. For instance, gelomulide K, a natural diterpene extract, induces a decrease in cellular GSH in cancer cells (41). It was also observed that ferulic acid potentiates the efficacy of radiosensitization in human cervical carcinoma cells by the attenuation of intracellular GSH (42). Similarly, we further observed the alteration of intracellular GSH levels in tumor cells after treatment with different concentrations of OA. The results showed that OA obviously reduces GSH levels in a concentration-dependent manner. Because $\gamma$-GCS is the key rate-limiting enzyme synthesizing intracellular GSH, the intracellular GSH level was decreased by inhibition of $\gamma$-GCS $(12,43)$. Our study demonstrated that the activity of $\gamma$-GCS in tumor cells could be downregulated following OA treatment. Although GSS is another synthetic enzyme of GSH, which is rarely considered in the field of radiation biology, we still observed its activity for the sake of clarifying the target of the radiosensitizing effect of OA. The experimental results found that OA does not evidently inhibit the activity of GSS. On the contrary, its activity was upregulated with $20 \% \mathrm{IC}_{50}$ of OA. Consequently, the synthesis of GSH in tumor cells was decreased via the downregulation of the activity of $\gamma$-GCS by OA, but not by the inhibition of GSS.

Data indicate that $\mathrm{MN}$ are the result of small chromosome fragments that are not incorporated into the daughter nuclei during cell division, which arise from exposure to nonrepaired or misrepaired DSBs by various clastogenic agents $(44,45)$. It has been suggested that DNA damage by ROS induction leads to formation of (SSBs) and DSBs $(46,47)$. Meanwhile, the number of radiation-induced $\mathrm{MN}$ was strongly correlated with radiation damage. The $\mathrm{MN}$ assay is an appropriate biological tool for evaluating the radiosensitivity of cells in vitro due to the good reliability and reproducibility of the assay (48). In the present study, treatment of OA alone did not statistically enhance the ratio of MN in tumor cells. Our results clearly showed that the ratio of MN was conspicuously increased when tumor cells were exposed to X-rays. Subsequently, it was found that the combination of OA at different concentrations and radiation led to higher ratios of $\mathrm{MN}$ compared to radiation alone. According to previous reports, the depletion of intracellular GSH results in the generation of MN. In order to verify this theory, NAC, an antioxidant and GSH precursor, was further used in our study. The outcome demonstrated that the level of intracellular GSH was enhanced after NAC was added to the culture medium, but no significant changes in $\gamma$-GCS and GSS activity were noted. The phenomenon was contributed to the enhancement of this enzymatic reaction substrate, but not the increasing activity of the enzymes by themselves (49). Moreover, concomitant with the enhancement of reduced GSH levels, the high ratios of $\mathrm{MN}$ with $\mathrm{OA}$ at $30 \% \mathrm{IC}_{50}$ concentration and irradiation treatment was decreased by NAC. Based on the high level of intracellular GSH, the following phenomenon was found. Compared to the cells without NAC pretreatment, both tumor cell lines treated with NAC showed a weaker damage after exposure to irradiation.

Importantly, previous data also indicate that OA attenuates hepatotoxicity and nephrotoxicity of various toxic agents by increasing the level of GSH, further protecting normal tissue and cells $(50,51)$. Conversely, our results and other studies indicate that high levels of GSH in tumor cells are markedly suppressed by pretreatment of OA and its derivatives $(52,53)$. Regarding this difference, we presume that the following factors possibly contributed to the controversial findings. The protective effect of $\mathrm{OA}$ and its derivatives are via the stimula- 
tion of the synthesis of GSH in normal tissues damaged by the depletion of GSH, while in contrast the effect of OA is through inhibition of GSH in malignant tumors with high levels of GSH. Since extremely high or low levels of GSH may disorder the redox equilibrium of the intracellular microenvironment (54), OA sustains the balance via regulation of GSH.

Taken together, our experimental results suggest for the first time that OA sensitizes rat glioma $\mathrm{C} 6$ cells and human lung cancer A549 cells to radiation in vitro. The mechanism of this sensitization may involve the inhibition of reduced GSH synthesis via the downregulation of $\gamma$-GCS activity, which in turn may explain the reduction in clonogenic survival and the increase in cellular MN. The effect of the natural medicine OA on regulating the radiation response may provide novel benefit for the treatment of tumors.

\section{Acknowledgements}

This study was financially supported by the China Postdoctoral Science Foundation (grant no. 201000470822) and Anhui Provincial Natural Science Foundation, China (grant no. $11040606 \mathrm{M} 210)$.

\section{References}

1. Shah C, Grills IS, Kestin LL, McGrath S, Ye H, Martin SK and Yan D: Intrafraction variation of mean tumor position during image-guided hypofractionated stereotactic body radiotherapy for lung cancer. Int J Radiat Oncol Biol Phys 82: 1636-1641, 2012.

2. Lagadec C, Vlashi E, Della Donna L, Meng Y, Dekmezian C, Kim K and Pajonk F: Survival and self-renewing capacity of breast cancer initiating cells during fractionated radiation treatment. Breast Cancer Res 12: R13, 2010.

3. Jamal M, Rath BH, Williams ES, Camphausen K and Tofilon PJ: Microenvironmental regulation of glioblastoma radioresponse. Clin Cancer Res 16: 6049-6059, 2010.

4. Ayouaz A, Raynaud C, Heride C, Revaud D and Sabatier L: Telomeres: hallmarks of radiosensitivity. Biochimie 90: 60-72, 2008.

5. Dumont F, Altmeyer A and Bischoff P: Radiosensitising agents for the radiotherapy of cancer: novel molecularly targeted approaches. Expert Opin Ther Pat 19: 775-799, 2009.

6. Bondza-Kibangou P, Millot C, El Khoury V and Millot JM: Antioxidants and doxorubicin supplementation to modulate CD14 expression and oxidative stress induced by vitamin $\mathrm{D}_{3}$ and seocalcitol in HL60 cells. Oncol Rep 18: 1513-1519, 2007.

7. Pani G, Galeotti T and Chiarugi P: Metastasis: cancer cell's escape from oxidative stress. Cancer Metastasis Rev 29: 351-378, 2010 .

8. Forkink M, Smeitink JA, Brock R, Willems PH and Koopman WJ: Detection and manipulation of mitochondrial reactive oxygen species in mammalian cells. Biochim Biophys Acta 1797: 1034-1044, 2010.

9. Forman HJ, Zhang H and Rinna A: Glutathione: overview of its protective roles, measurement, and biosynthesis. Mol Aspects Med 30: 1-12, 2009.

10. Circu ML and Aw TY: Glutathione and apoptosis. Free Radic Res 42: 689-706, 2008.

11. Wu G, Fang YZ, Yang S, Lupton JR and Turner ND: Glutathione metabolism and its implications for health. J Nutr 134: 489-492, 2004.

12. Botta D, White CC, Vliet-Gregg P, et al: Modulating GSH synthesis using glutamate cysteine ligase transgenic and genetargeted mice. Drug Metab Rev 40: 465-477, 2008.

13. Zhang W, Trachootham D, Liu J, et al: Stromal control of cystine metabolism promotes cancer cell survival in chronic lymphocytic leukaemia. Nat Cell Biol 14: 276-286, 2012.

14. Lewis-Wambi JS, Kim HR, Wambi C, Patel R, Pyle JR, KleinSzanto AJ and Jordan VC: Buthionine sulfoximine sensitizes antihormone-resistant human breast cancer cells to estrogeninduced apoptosis. Breast Cancer Res 10: R104, 2008.
15. Ogunrinu TA and Sontheimer H. Hypoxia increases the dependence of glioma cells on glutathione. J Biol Chem 285: 37716-37724, 2010.

16. Ruiz-Gómez MJ, Souviron A, Martínez-Morillo M and Gil L: P-glycoprotein, glutathione and glutathione S-transferase increase in a colon carcinoma cell line by colchicine. J Physiol Biochem 56: 307-312, 2000.

17. Inci E, Civelek S, Seven A, Inci F, Korkut N and Burçax G: Laryngeal cancer: in relation to oxidative stress. Tohoku J Exp Med 200: 17-23, 2003.

18. Honda T, Coppola S, Ghibelli L, et al: GSH depletion enhances adenoviral bax-induced apoptosis in lung cancer cells. Cancer Gene Ther 11: 249-255, 2004.

19. Simons AL, Parsons AD, Foster KA, Orcutt KP, Fath MA and Spitz DR: Inhibition of glutathione and thioredoxin metabolism enhances sensitivity to perifosine in head and neck cancer cells. J Oncol 2009: 519563, 2009.

20. Boivin A, Hanot M, Malesys C, Maalouf M, Rousson R, Rodriguez-Lafrasse $\mathrm{C}$ and Ardail D: Transient alteration of cellular redox buffering before irradiation triggers apoptosis in head and neck carcinoma stem and non-stem cells. PLoS One 6: e14558, 2011.

21. Pollier J and Goossens A: Oleanolic acid. Phytochemistry 77: 10-15, 2012.

22. Yang EJ, Lee W, Ku SK, Song KS and Bae JS: Anti-inflammatory activities of oleanolic acid on HMGB1 activated HUVECs. Food Chem Toxicol 50: 1288-1294, 2012.

23. Reisman SA, Aleksunes LM and Klaassen CD: Oleanolic acid activates Nrf2 and protects from acetaminophen hepatotoxicity via Nrf2-dependent and Nrf2-independent processes. Biochem Pharmacol 77: 1273-1282, 2009.

24. Yim TK, Wu WK, Pak WF and Ko KM: Hepatoprotective action of an oleanolic acid-enriched extract of Ligustrum lucidum fruits is mediated through an enhancement on hepatic glutathione regeneration capacity in mice. Phytother Res 15: 589-592, 2001.

25. Hsu HY, Yang JJ and Lin CC: Effects of oleanolic acid and ursolic acid on inhibiting tumor growth and enhancing the recovery of hematopoietic system postirradiation in mice. Cancer Lett 111: 7-13, 1997.

26. Fujiwara Y, Komohara Y, Kudo R, Tsurushima K, Ohnishi K, Ikeda $\mathrm{T}$ and Takeya M: Oleanolic acid inhibits macrophage differentiation into the M2 phenotype and glioblastoma cell proliferation by suppressing the activation of STAT3. Oncol Rep 26: 1533-1537, 2011.

27. Wei J, Liu H, Liu M, et al: Oleanolic acid potentiates the antitumor activity of 5-fluorouracil in pancreatic cancer cells. Oncol Rep 28: 1339-1345, 2012.

28. Bishayee A, Ahmed S, Brankov N and Perloff M: Triterpenoids as potential agents for the chemoprevention and therapy of breast cancer. Front Biosci 16: 980-996, 2011.

29. Yamai H, Sawada N, Yoshida T, et al: Triterpenes augment the inhibitory effects of anticancer drugs on growth of human esophageal carcinoma cells in vitro and suppress experimental metastasis in vivo. Int J Cancer 125: 952-960, 2009.

30. White CC, Viernes H, Krejsa CM, Botta D and Kavanagh TJ: Fluorescence-based microtiter plate assay for glutamate-cysteine ligase activity. Anal Biochem 318: 175-180, 2003.

31. Frosina G: DNA repair and resistance of gliomas to chemotherapy and radiotherapy. Mol Cancer Res 7: 989-999, 2009.

32. Chang JY and Cox JD: Improving radiation conformality in the treatment of non-small cell lung cancer. Semin Radiat Oncol 20: 171-177, 2010.

33. Kim M, Lee J, Ha B, Lee R, Lee KJ and Suh HS: Factors predicting radiation pneumonitis in locally advanced non-small cell lung cancer. Radiat Oncol J 29: 181-190, 2011.

34. Zerp SF, Stoter R, Kuipers G, et al: AT-101, a small molecule inhibitor of anti-apoptotic Bcl-2 family members, activates the SAPK/JNK pathway and enhances radiation-induced apoptosis. Radiat Oncol 4: 47, 2009.

35. Rao SK, Rao PS and Rao BN: Preliminary investigation of the radiosensitizing activity of guduchi (Tinospora cordifolia) in tumor-bearing mice. Phytother Res 22: 1482-1489, 2008.

36. Dai Y, DeSano JT, Meng Y, Ji Q, Ljungman M, Lawrence TS and $\mathrm{Xu}$ L: Celastrol potentiates radiotherapy by impairment of DNA damage processing in human prostate cancer. Int J Radiat Oncol Biol Phys 74: 1217-1225, 2009.

37. Tsai SJ and Yin MC: Anti-oxidative, anti-glycative and antiapoptotic effects of oleanolic acid in brain of mice treated by D-galactose. Eur J Pharmacol 689: 81-88, 2012. 
38. Koh SJ, Tak JK, Kim ST, Nam WS, Kim SY, Park KM and Park JW: Sensitization of ionizing radiation-induced apoptosis by ursolic acid. Free Radic Res 46: 339-345, 2012.

39. Eder-Czembirek C, Erovic BM, Czembirek C, Brunner M, Selzer E, Pötter R and Thurnher D: Betulinic acid a radiosensitizer in head and neck squamous cell carcinoma cell lines. Strahlenther Onkol 186: 143-148, 2010.

40. Selzer E, Pimentel E, Wacheck V, Schlegel W, Pehamberger H, Jansen B and Kodym R: Effects of betulinic acid alone and in combination with irradiation in human melanoma cells. J Invest Dermatol 114: 935-940, 2000.

41. Yang JC, Lu MC, Lee CL, Chen GY, Lin YY, Chang FR and Wu YC: Selective targeting of breast cancer cells through ROS-mediated mechanisms potentiates the lethality of paclitaxel by a novel diterpene, gelomulide K. Free Radic Biol Med 51: 641-657, 2011.

42. Karthikeyan S, Kanimozhi G, Prasad NR and Mahalakshmi R: Radiosensitizing effect of ferulic acid on human cervical carcinoma cells in vitro. Toxicol In Vitro 25: 1366-1375, 2011.

43. Benassi B, Zupi G and Biroccio A: Gamma-glutamylcysteine synthetase mediates the c-Myc-dependent response to antineoplastic agents in melanoma cells. Mol Pharmacol 72: 1015-1023, 2007.

44. Oliveira NG, Castro M, Rodrigues AS, et al: Wortmannin enhances the induction of micronuclei by low and high LET radiation. Mutagenesis 18: 37-44, 2003.

45. Sedelnikova OA, Nakamura A, Kovalchuk O, et al: DNA double-strand breaks form in bystander cells after microbeam irradiation of three-dimensional human tissue models. Cancer Res 67: 4295-4302, 2007.

46. Kashino G, Prise KM, Suzuki K, et al: Effective suppression of bystander effects by DMSO treatment of irradiated CHO cells. J Radiat Res 48: 327-333, 2007.
47. Shao C, Furusawa Y, Kobayashi Y, Funayama T and Wada S: Bystander effect induced by counted high-LET particles in confluent human fibroblasts: a mechanistic study. FASEB J 17: 1422-1427, 2003.

48. Thierens $\mathrm{H}$ and Vral A: The micronucleus assay in radiation accidents. Ann Ist Super Sanita 45: 260-264, 2009.

49. McConnachie LA, Mohar I, Hudson FN, et al: Glutamate cysteine ligase modifier subunit deficiency and gender as determinants of acetaminophen-induced hepatotoxicity in mice. Toxicol Sci 99: 628-636, 2007.

50. Bai X, Qiu A, Guan J and Shi Z: Antioxidant and protective effect of an oleanolic acid-enriched extract of A. deliciosa root on carbon tetrachloride induced rat liver injury. Asia Pac J Clin Nutr 16 (Suppl 1): 169-173, 2007.

51. Abdel-Zaher AO, Abdel-Rahman MM, Hafez MM and Omran FM: Role of nitric oxide and reduced glutathione in the protective effects of aminoguanidine, gadolinium chloride and oleanolic acid against acetaminophen-induced hepatic and renal damage. Toxicology 234: 124-134, 2007.

52. Petronelli A, Saulle E, Pasquini L, et al: High sensitivity of ovarian cancer cells to the synthetic triterpenoid CDDO-imidazolide. Cancer Lett 282: 214-228, 2009.

53. Ikeda T, Sporn M, Honda T, Gribble GW and Kufe D: The novel triterpenoid CDDO and its derivatives induce apoptosis by disruption of intracellular redox balance. Cancer Res 63: 5551-5558, 2003.

54. Haddad JJ, Olver RE and Land SC: Antioxidant/pro-oxidant equilibrium regulates HIF-1alpha and NF-kappa B redox sensitivity. Evidence for inhibition by glutathione oxidation in alveolar epithelial cells. J Biol Chem 275: 21130-21139, 2000. 